\title{
The Good Fairy Problem: One More Look at the Optimum Rotation Age for a Forest Stand
}

by

David E.N. Tait ${ }^{1}$

\begin{abstract}
The good fairy problem reexamines the question of the optimum age to harvest a stand of trees. The metaphor of a financial portfolio reveals the sense in which the financial rotation age is optimal and the sense in which the rotation age that maximizes the mean annual increment in net value is optimal. This metaphor clarifies the distinction between economic efficiency and forest policy. In particular, it indicates the ultimate inevitability of the financial rotation age while demonstrating that the financial rotation age implicitly rejects the notion of sustained yield. A sustained yield forest with a financial rotation age is not economically optimum.
\end{abstract}

\section{Résumé}

Une bonne vieille fable refait état de la question de l'âge optimal d'exploitation d'un peuplement forestier. La métaphore d'un portefeuille financier révèle une version où l'âge de la rotation financière est optimum et une version où l'âge de la rotation maximisant l'accroissement annuel moyen en valeur net est l'optimum. Cette métaphore fait la distinction entre l'efficience économique et les politiques forestières. Plus particulièrement, elle indique l'ultime inévitable de la rotation basée sur l'âge financier tout en démontrant que l'âge de la rotation financière rejette implicitement la notion de rendement soutenu. Un rendement soutenu en foresterie associé à l'âge de la rotation financière n'est pas économiquement optimal.

\section{Introduction}

Samuelson (1976) entered the debate of the "economics of forestry in an evolving society" and came down squarely behind such concepts as a financial rotation age. In Samuelson's debate economists were on one side, and forestry experts along with the general public on the other. Samuelson was not the first to explore the consequences of economic reasoning in the area of forest management. He essentially agreed with the analyses done by Martin Faustmannn in 1849, Gaffney (1960), Bentley and Teeguarden (1965), and Pearse (1967). Nor was Samuelson the last to examine the optimal cutting age for a stand; Johansson and Lofgren (1985) provide a recent review of the problem.

Foresters have come a long way since Samuelson (1976) suggested that their assumed goal was "maximum sustained yield". By now most foresters are aware of concepts such as the financial rotation age and Faustmann's solution to the rotation age problem.

The justification for yet another paper on the optimum rotation age for a forest stand is the result of a thought experiment called the good fairy problem. I have presented the good fairy problem to a number of faculty members in forestry, graduate students in forest economics, and undergraduate students in forest management. In this thought experiment the normal forest is treated in much the same way as an "ideal gas" is treated in chemistry or a "freely falling

Department of Harvesting and Wood Science. University of British Columbia, Vancouver, BC, Canada V6T IW5 elevator" is treated in physics. The normal forest is used to check the consistency of one's ideas. In spite of the good fairy's very restrictive and simplifying set of assumptions, most of the people surveyed gave the wrong answer. In particular, those surveyed did not seem to appreciate that Samuelson was not simply attacking the notion of maximum sustained yield, but rather was attacking the notion of sustained yield in general.

The "good fairy" problem is presented here to clarify the distinction between stand management and forest management. In particular, it is expected that the reader will have a better understanding of the implications of the financial rotation age.

\section{The Good Fairy Problem}

In the good fairy problem you are greeted by the good fairy and informed that she will construct a forest on your behalf. This forest will be an idealized normal forest with an equal representation by area of each age class. The good fairy also informs you that for this particular forest the standard assumptions that economists like to make pertain. In particular one can assume that the future net value is only a function of age. This means that future timber prices and harvesting costs are fixed and known. The good fairy problem gives you a net value over age curve that is assumed to be appropriate for all stands in the forest and for all time. She also informs you that the interest rate is known and will be constant over all future time. In the forest that the good fairy will set up there are no externalities or multiple objectives to worry about. This means that there are no environmental, aesthetic, labor or social factors of concern. Finally, the good fairy indicates 
that she will manage the forest on your behalf as a sustained yield forest. Every year she will cut the oldest age class, regenerate the stand, and give you the net return from the harvest. All that she wants from you is the rotation age to be used in this forest. She, with her magic wand, will set up the corresponding normal forest and begin managing it for you. The good fairy problem is "What rotation age would you use?".

Most of the faculty, graduate forest economic students and undergraduate students that I surveyed indicated that they would compute the financial rotation age using the value over age curve and the given interest rate. The financial rotation age, $T_{F}$, is the rotation age for a stand that maximizes the net present value of a time stream of harvests, with the first harvest in $T_{F}$ years. In the survey I asked people that gave this answer whether they were sure. "After all a silviculturist, presented with the same problem, chose an age corresponding to the maximum mean annual increment in net value." The economists, in defence of the financial rotation age, generally suggested that the silviculturist didn't understand interest rates or had ignored the economic rent on the land. The more sophisticated economists, in defence of the financial rotation age, would quote Samuelson (1976) or go through the arguments that prove that the financial rotation age, with the above assumptions, represents the optimal management of a stand.

The good fairy problem continues with the "economist" and "silviculturist" both being granted equal area forests. The stands in the "economist's" forest are being managed by the good fairy with the financial rotation age and the stands in the "silviculturist's" forest are being managed with a rotation age that maximizes the mean annual increment in net value. The good fairy takes care of the forests and harvests the stands. She pays the "silviculturist" and the "economist" with bags of gold representing the net value of the yearly harvest. The "economist" can't help but notice each year as he is depositing his bag of gold in the bank that the "silviculturist" is depositing a slightly larger bag of gold. In the bank the "economist" and the "silviculturist" both experience the same interest rate. With the higher yearly deposit, the net present value of the "silviculturist's" policy is higher then the net present value of the "economist's" policy.

The good fairy problem is a trick question, designed in particular to trick forestry students. Its success as a trick question is a consequence of the following apparent dilemma. On the one hand a normal forest with stands managed with a rotation age that maximizes the mean annual increment in net value yields a higher return than the same sized normal forest with stands managed with a rotation age equal to the financial rotation age. On the other hand the financial rotation age represents the financially optimum age to harvest a stand. The apparent dilemma is that the "silviculturist" is getting a larger financial return from his forest than the "economist" but the "silviculturist" is not managing his stands in a financially optimal manner.

\section{Resolution}

The resolution of this apparent contradiction helps to clarify the concept of the financial rotation age. To begin with, the "silviculturist" is making more money. At a rotation age T, the net revenue generated from a forest of $A$ hectares would be:

$$
V(T) \times A / T
$$

Every year $\mathrm{A} / \mathrm{T}$ hectares would be harvested with a yield of $\mathrm{V}(\mathrm{T})$ dollars per hectare. The average per hectare net value for the whole forest would thus be V(T)/T. Gregory (1972) refers to the average per hectare net value for the forest as the forest rent. $\mathrm{V}(\mathrm{T}) / \mathrm{T}$ is the slope of the line from the origin to the curve $V(T)$ at rotation age $T$ (Figure 1). The slope of this line also represents the average annual increment in net value per hectare over the life of a stand at age T. The maximum mean annual increment in net value (as opposed to volume) is thus equivalent to the maximum average per hectare net yield (in dollars). This maximum average per hectare net yield corresponds to the maximum slope for a line from the origin to the curve $V(T)$ and is shown as the tangent line to the curve $V(T)$ in Figure 1. The "silviculturist's" rotation age $T_{\text {MAI }}$ which maximizes $\mathrm{V}(\mathrm{T}) / \mathrm{T}$, thus maximizes the forest rent, the average per hectare yield from the forest (Gregory 1972). The average per hectare monetary yield or the yearly yield from the forest using the silviculturist's rotation age is higher than the yield from a forest managed with any other rotation age, including the financial rotation age $T_{F}$.

To see in what way the financial rotation age is optimal it is only necessary to think of the $T$ stands as representing $T$ assets in a financial manager's diverse portfolio. In this simplistic portfolio metaphor the manager examines each asset's value to determine whether he should liquidate it or keep it. Risk and other factors are ignored. "Liquidating an asset" will be defined to mean trading in the stand for its total current net present value. The total current net present value is the net value of the harvest plus the site expectation of the stand. The site expectation is the present value of all of the future harvests of the stand assuming that the stand is managed with a constant rotation age. The value of liquidating an asset thus corresponds to the value of the commitment to harvest the stand now and every $T$ years. The liquidated value is equivalent in value to the present value of a bond or annuity that pays out $\mathrm{V}(T) \times A / T$ dollars every $T$ years. In this annuity, the first payment takes place immediately. Using the assumptions that economists like to make, the manager could sell his rights to the stand for what they are worth and invest the liquidated value in a bank at the interest rate supplied by the good fairy.

The rational financial manager will manage his portfolio optimally. (My interpretation of rational simply means that the individual will choose those actions that leave him better off.)

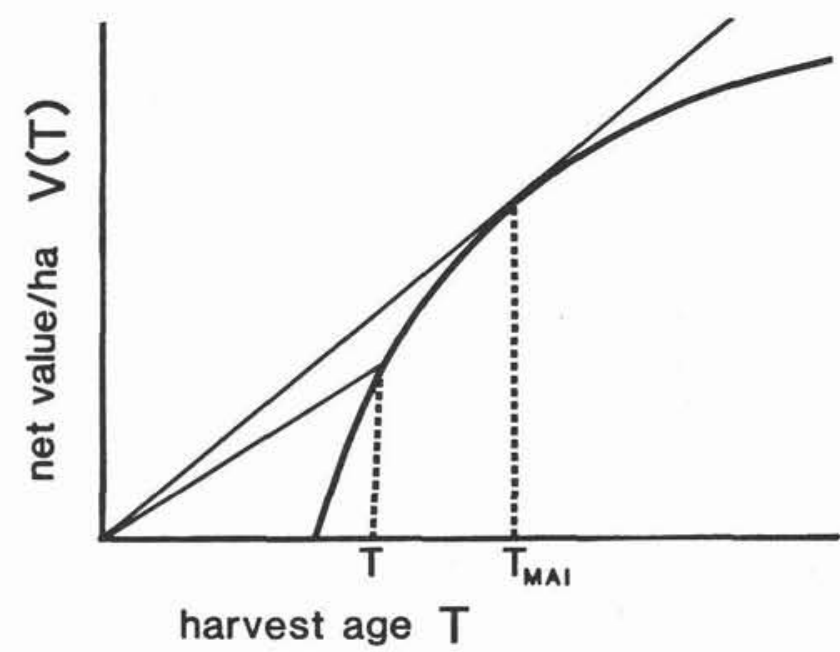

Figure 1. Net Harvest Value. The forest rent and maximum forest rent are represented by the slope and the maximum slope of the lines from the origin to the net value curve. 
The financial manager will each year examine each of his options in his portfolio and will keep all options that are increasing in value at a rate that is higher than the given interest rate. He will liquidate a particular asset (harvest a stand) if he is better off investing the returns at the going interest rate. It should be kept in mind that in this metaphor the liquidated value is not just the harvest value of the stand but also includes the site value which is the present value of future harvests. This decision is a stand level decision made on a yearly basis. It involves no particular policy except to choose actions that leave one better off. The rational manager will not harvest a stand as long as the asset representing the unharvested stand is increasing in value at a rate that is higher than the interest rate. Using this strategy, the manager will end up harvesting stands at the financial rotation age (see Appendix).

In the portfolio metaphor, the standing forest represents invested capital. The financial manager is making optimal use of his capital. He is only leaving it in investments that are earning more than the interest rate that he could get elsewhere.

The "silviculturist", on the other hand, with a longer rotation age, has a more valuable portfolio. The total capital value of all of his assets is larger than the "economist's". For the "silviculturist" there are some stands with large, more valuable trees. The "silviculturist" is also receiving a larger yearly dividend from his portfolio of assets. Although the area of the "silviculturist's" stand, $A / T_{\text {MAI }}$ is smaller than the area of the "economist's" stand, $A / T_{F}$, the value of the yearly harvest is larger. The "silviculturist" has chosen to maximize $V(T) / T$. $\mathrm{He}$ has chosen to maximize his forest rent. He has chosen a forest that maximizes his yearly dividend. However, the rate of return, the ratio of the dividend to the principal or capital value of his assets is lower for the silviculturist than it is for the economist. The "silviculturist" has some stands in his portfolio that are increasing in value at a rate that is lower than the going interest rate. It is in this sense that the silviculturist is not optimally managing his assets. He would be better off if he could liquidate the stands that are over the financial rotation age and invest the returns at the going interest rate.

The above observation reveals the "trick" that is in the good fairy problem. The good fairy has generated a forest with a constraint. The owner is not allowed to liquidate the forest. He may only pocket the interest. The silviculturist has chosen a forest with a larger principal which, even with a lower interest rate, provides a larger interest payment or dividend. The economist on the other hand by using a shorter rotation age has been tricked into asking for a forest with a smaller average value. The only virtue in the economist's forest is that, partly as a result of the relatively low value of the standing timber, the economist is making a good rate of return.

In fairness to the caricatured economist, some good economists did get the correct solution to the good fairy problem. Maximizing the net present value of a steady stream of harvests from a constant area forest yields the silviculturist's solution. Maximizing the net present value is equivalent to maximizing the yearly dividend or harvest value.

However, the best "economic" answer, given a choice between a normal forest with stands harvested at the financial rotation age and a normal forest with stands harvested at the maximum mean annual value increment rotation age, would be to choose the maximum mean annual value increment rotation age and cheat. Cheating in this case would be going out, when the good fairy isn't looking, harvesting those stands that are over the financial rotation age, and depositing the returns at the current interest rate. Such a strategy would have a higher net present value than either the economist's or the silviculturist's strategy.

The good fairy problem represents a very specific situation. It represents a normal forest, a sustained yield policy, and no conversion costs in setting up the forest. Expanding the complexity of the problem slightly reveals that the optimum economic solution in general for a sustained yield forest is to use neither the financial rotation age nor the maximum forest rent rotation age in managing the forest stands. The optimum forest management policy depends on the current inventory, the conversion policy, the stand values, and the interest rate.

The interdependency of the conversion rate, the conversion value and the optimum rotation age can be clearly demonstrated by again using a simple thought model. One can imagine taking $T$ years to convert an old growth forest to a normal forest that would then be managed on a sustained yield basis. The conversion period of $T$ years has a net present value of an annuity that pays a yearly dividend of $V_{0} A / T$. where $V_{0}$ is the net conversion harvest value per hectare. The post-conversion period is a second annuity that pays $V(T) A / T$ per year starting in year $T$. Maximizing the net present value of these two annuities combined with respect to T can be shown to depend on $V_{0}$. Nautiyal and Fowler (1980) developed a similar argument, but in a more complicated setting.

\section{Conclusions}

A number of observations are revealed by the above metaphor. The first is that the financial rotation age is not something that needs to be set by policy. It need not be thought of as a prescription but rather as a description. It is the end point that will be reached by rational choice. Owners of the resource will harvest stands over the financial rotation age because they will be better off. Stands under the financial rotation age will be left. For the younger stands the forest owner will be better off borrowing at the current interest rate. With this interpretation, the financial rotation age need not be thought of as a "rotation" age. Rather, it represents the economically efficient harvest age. It should be clear that the harvest age will change as prices, costs, and interest rate change. It only becomes a fixed "rotation" age if these economic variables are constant over time.

The converse is worth stressing as well. A policy is required if it is desirable to avoid the economic efficient solution. A policy is implemented if the economically efficient solution is socially unacceptable or if there are "externalities" that are not reflected in the harvest revenue. However, any policy to maintain a stand above its financial rotation age will be at risk. Such a policy would need to be maintained and would require an active investment of controls. Somewhere, at some time, the owner of the forest resource, whether public or private, will have a need for capital. He will liquidate those stands that are over the financial rotation age. If there is a policy to resist such actions, at some time someone will cheat.

The third observation is that the value in liquidating stands that are over the financial rotation age lies only in the value of investing the liquidated capital. There is nothing inherently valuable in a stand at the financial rotation age or in a forest that is made up of stands that are managed at the financial rotation age. Such a forest may represent a small 
capital asset with a small annual dividend. Its only inherent feature is that the ratio of dividend to principal is high.

The fourth observation is to note that the good fairy imposed a policy. The policy was only that the forest was to be managed on a sustained yield basis. Given this policy the good fairy was willing to take care of the conversion costs. Nautiyal and Pearse (1967) point out that the optimum sustained yield forest rotation age solution is dependent on the conversion period and the state of the original forest. In the good fairy problem, with zero conversion costs the optimum economic solution with the sustained yield policy constraint is to maximize the forest rent. The appropriate rotation age is the silviculturist's rotation age.

Economic arguments such as those proposed by Samuelson (1976) are not arguements about the merits of one rotation age versus another in a sustained yield forest. The argument presented by Samuelson is not whether to have maximum sustained yield or sustained yield that is based on a financial rotation age. Samuelson was arguing against any sustained yield policy. The debate about the optimum rotation age needs to be refocussed to a debate about the merits of sustained yield or the relative merits of having a regulated timber supply.

In summary, the good fairy problem in conjunction with the asset portfolio metaphor reveals that the optimum rotation for a sustained yield forest is not the financial rotation age. The economically optimum solution to the good fairy problem represents the maximum forest rent. Gregory (1972) has characterized this particular solution as "...bad economics, bad business, and bad forestry..." and "...deserves no serious consideration in courses concerned with forest economics or forest management." However, in the context of a sustained yield policy with no conversion costs the maximum forest rent solution is the optimum economic solution. However, the intent in developing this particular illustrative example is not to rekindle the debate between forest rent and site expectation. Nor is it intended to suggest that one should manage a forest to maximize the forest rent. In the context of a forest policy, neither solution is likely to be economically optimal. The problem is intended to illustrate that it is not appropriate to apply "text book" solutions to economic analysis. What is necessary is a clear understanding of the economic principles and an understanding of how to correctly carry out an economic analysis in the context of a policy constraint.

\section{Acknowledgements}

This research was supported in part by a grant from the Natural Sciences and Engineering Research Council of Canada. I would also like to thank the faculty and students who were willing to be accosted by the good fairy. Finally, I would like to acknowledge the contribution of Mr. Doug Walker for his review of an earlier draft. I believe his suggestions have led to a clearer set of arguments.

\section{Appendix}

The traditional development of the financial rotation age maximizes the computed land value, the present value of bare land that will be harvested every T years. The land value, LV $(T)$, is an annuity that differs from the asset value annuity described in the text in that it is missing the first dividend. The land value as a function of the rotation age is:

$$
L V(T)=A V(T)-V(T)
$$

where LV, AV, and V are the bare land value, the asset value, and the net harvest value respectively. The first order condition for a maximum is:

$$
\begin{array}{rlrl} 
& & L V^{\prime}(T)=A V^{\prime}(T)-V^{\prime}(T)=0 \\
\text { or } & V^{\prime}(T)=A V^{\prime}(T)
\end{array}
$$

The land value $L V(T)$, is also the value of the asset $A V(T)$ discounted $T$ years:

$$
\operatorname{LV}(T)=A V(T) \times e^{-1 T}
$$

where $i$ is the instantaneous discount rate. The LV annuity is equivalent to an $\mathrm{AV}$ annuity starting $T$ years in the future. The first order condition for a maximum in this case is:

$$
\begin{array}{rlrl}
\text { or } & & L V^{\prime} T & =(T) e^{-1 T}-i A V(T) e^{-1 T}=0 \\
\text { o } & A V^{\prime} T & =i A V(T)
\end{array}
$$

Substituting equation 2 into equation 1 yields:

$$
V^{\prime}(T)=i A V(T)
$$

The financial rotation age, the rotation age that maximizes the bare land value, is the solution to equation 3 . In other treatments of this problem $A V(T)$ in equation 3 is left as the sum of the harvest value, $\mathrm{V}(\mathrm{T})$, and the land value, $\mathrm{LV}(\mathrm{T})$.

In the text the silviculturist's rotation age was identified as being better than the economist's because every year the silviculturist received a larger revenue from his forest. However, the silviculturist's rotation age may be derived using the standard economic analysis. The economically optimal harest age would be the havest age that maximizes the net present value of the time stream of harvest values. This time stream of harvest values represents an annuity with a yearly premium of $\mathrm{V}(\mathrm{t}) \mathrm{A} / \mathrm{t}$ where $\mathrm{V}(\mathrm{t})$ is the net harvest value per hectare at age $t, A$ is the forest area and $A / t$ is the stand area. The net present value, $N P V(t)$, using an interest rate $i$, is given by:

$$
N P V(t)=\frac{V(t) A i}{t(1+i)}
$$

The maximum is found by setting to zero the derivative of $N P V(t)$ with respect to $t$. The first order condition for a maximum in this case is:

$$
V^{\prime}(t)=V(t) / t
$$

The rotation age that satisfies this equation is the rotation age that maximizes the forest rent and is not the financial rotation age. In Figure 1 , at the optimum, the slope of the line from the origin to the curve $V(t)$ is equal in value to the tangent of the curve, $V^{\prime}(t)$.

\section{References}

Bentley, W.R. and D.E. Teeguarden. 1965. Financial maturity: a theoretical review. For. Sci. 11: 76-87.

Faustmann, M. 1849. Calculation of the value which forest land and immature stands pose for forestry. English edition edited by $\mathrm{M}$. Cane, Univ. Oxford Common. For. Pap 42, 1968, 'Martin Faustmann and the evolution of discounted cash flow.' pp2755

Gaffney, M. 1960. Concepts of financial maturity of timber and other assets. A.E. Inf Series No. 62, North Carolina State College. Raleigh. 105pp.

Gregory, G.R. 1972. Forest Resource Economics. Ronald Press. New York. 548pp.

Johansson, P.O. and K.G. Lofgren. 1985. The Economics of Forestry and Natural Resources. Basil Blackwell Ltd. Oxford. 292pp.

Nautiyal, J.C. and K.S. Fowler. 1980. Optimum forest rotation in an imperfect stumpage market. Land Econ. 56: 213-226.

Nautiyal, J.C. and P.H. Pearse. 1967. Optimizing the conversion to sustained yield - a programming solution. For. Sci. 13: 131. 139.

Pearse, P.H. 1967. The optimum forest rotation. For. Chron. 43: 178195.

Samuelson, P.A. 1976. Economics of forestry in an evolving society. Econ. Inq. 14: 466-492. 